\title{
Apropriação de Mídias Sociais: uma Proposta de Modelo de Análise
}

\section{Appropriation of Social Media: a Proposal for Analysis Model}

\author{
Adriano Santos Rocha Silva ${ }^{1}$, Ernani Marques dos Santos ${ }^{1}$ \\ ${ }^{1}$ Universidade Federal da Bahia, UFBA, Brasil \\ Correspondência: Adriano Santos Rocha Silva. Endereço: Ondina, Salvador - BA, 40170-115 Telefone: (71) \\ 3283-7072 E-mail: adrianorocha70@gmail.com
}

Recebido: 04 de dezembro de 2017 Aceito: 15 de dezembro de 2017 Publicado: 31 de dezembro de 2017

DOI: http://dx.doi.org/10.21714/1679-18272017v15Ed.p171-183

\begin{abstract}
Resumo
O presente artigo objetiva propor um modelo de análise do processo de apropriação de tecnologias de mídias sociais. Tal proposta baseia-se em estudos realizados sobre apropriação de tecnologias, processo de adaptação e ajuste destas de acordo com os interesses, necessidades e conveniências de quem as utiliza. O modelo busca identificar características peculiares no processo de apropriação de mídias sociais por empresas, englobando tanto os Fatores de Adoção, no primeiro estágio do processo, quanto os Fatores Intermediários, que envolvem a exploração e a adaptação da tecnologia (uso, portanto), até os Fatores Reforçadores, fundamentais para a consolidação da apropriação ou não e que ocorrem por ocasião da experiência. Para tanto, são apresentados modelos teóricos sobre o tema e, por fim, um modelo que permita observar e compreender a apropriação especificamente de mídias sociais por empresas usuárias, a partir do Modelo de Apropriação de Tecnologia (MTA) de Carroll et al. (2002) e Carroll (2004).
\end{abstract}

Palavras-chave: Apropriação; Mídias Sociais; Tecnologia.

\begin{abstract}
The purpose of this article is to propose a model for analyzing the process of appropriation of social media technologies. This proposal is based on studies on the appropriation of technologies, the process of adaptation and adjustment of these according to the interests, needs and conveniences of those who use them. The model seeks to identify peculiar characteristics in the process of appropriation of social media by companies, covering both the Adoption Factors, in the first stage of the process, and the Intermediate Factors, which involve the exploration and adaptation of the technology (use, therefore), and Reinforcement factors, fundamental for the consolidation of the appropriation or not, and that occur during the experience. For this, theoretical models are presented on the subject and, finally, a model that allows to observe and to understand the appropriation specifically of the social media by the user companies, of the Model of Appropriation of Technology (MTA) of Carroll et al. (2002) and Carroll (2004).
\end{abstract}

Keywords: Appropriation; Social Medias; Technology.

\section{INTRODUÇÃO}

As décadas que abrangem o final do Século XX e o início do XXI têm sido pródigas no avanço da tecnologia em todas as áreas, mas com um forte destaque para as tecnologias de informação e comunicação (TIC). Tendo a Internet como ferramenta central, elas têm oferecido à sociedade uma grande quantidade de inovações, dando à área de sistemas de informação (SI) um dinamismo cada vez maior. Boa parte das primeiras pesquisas neste campo considerava que as tecnologias eram fixas, podendo ser mudadas apenas por seus desenvolvedores (CARROLL et al., 2001). Com o tempo, no entanto, foi-se percebendo que os usuários não apenas utilizavam as TIC como também as adaptavam e até as modificavam conforme suas necessidades, personalizando-as e usandoas para novos fins. Foi possível constatar, assim, que essas modificações levavam a uma disparidade entre os propósitos e objetivos de quem desenvolve a tecnologia e seu uso real (CARROLL et al., 2001). A esse processo 
pelo qual os usuários de uma tecnologia a adotam, testam suas possibilidades e a modificam, de forma menos ou mais radical, para satisfazer suas necessidades ou desejos é dado o nome de apropriação (BAR; PISANI; WEBER, 2007).

A apropriação de tecnologia pode ser caracterizada desde por sutis modificações estéticas ou estruturais que não interferem em sua função original, até extremos acréscimos funcionais que resultem numa transformação tanto da tecnologia quanto da própria atividade desempenhada por ela (ARAÚJO, 2013). Um exemplo para o caso de modificações sutis é observado quando um usuário seleciona em seu telefone celular um toque diferente daquele original de fábrica. Embora altere uma configuração do aparelho, o novo toque não afeta sua função como instrumento de comunicação. Já um exemplo para os casos de modificação extrema pode ser o uso do telefone celular em Uganda, na África, onde foi observado que as pessoas usavam o serviço de Short Message Service (SMS) para transferência informal de valores monetários por meio de compra de créditos de telefonia móvel. Ou seja, mesmo mantendo-se a função do SMS intacta como instrumento de comunicação, uma nova função foi agregada a ele pelos usuários ugandenses como forma de satisfazer uma necessidade cotidiana (ARAÚJO, 2013).

A apropriação de tecnologia é considerada, então, "um movimento que acontece em um processo dinâmico, que pode envolver momentos de adaptação e reinvenção de significados" (RODRIGUEZ, 2006, p. 38), sendo parte integrante de um processo construído na interação entre os atores sociais envolvidos. Esse processo, no entanto, não se limita à ação de indivíduos, mas também a de organizações, uma vez que estas buscam satisfazer suas diferentes necessidades mediante a adoção, o uso e a adaptação de tecnologias por funcionários de suas diversas áreas internas (ARAÚJO, 2012).

Recentemente, o avanço das tecnologias de informação e comunicação adquiriu uma forte projeção com o surgimento e a proliferação das mídias sociais. Esta nova concepção de uso das TIC como meio de proporcionar interação entre usuários e organizações tornou as emergentes mídias sociais potenciais canais de relacionamento devido à sua flexibilidade, rapidez e alcance, além de possibilitar o compartilhamento de conteúdos (SAAD CORRÊA, 2009). Prova disso é o número crescente de empresas de todos os portes que têm lançado mão dessas mídias para se relacionar com seus respectivos clientes, fornecedores, funcionários e público-alvo de modo mais direto, ágil, interativo e preciso; e para a obtenção de informações mais rápidas e concisas.

Esse crescimento do uso das mídias sociais constitui-se um fenômeno global que está se espalhando por todas as partes e tem nas empresas um alvo certo por serem um importante instrumento de marketing. Mais do que isso, as mídias sociais têm proporcionado às empresas novas ferramentas de relacionamento, alcance de diferentes mercados e segmentação de campanhas de acordo com os perfis de seus usuários e comunidades (SMITH, 2009). Qualman (2011) afirma que uma empresa não tem mais a opção de escolher se quer ou não participar das mídias sociais, seu esforço diz respeito a quão eficaz será essa participação.

Dentre as mídias sociais existentes na Internet, o Facebook ocupa uma posição de liderança e é o segundo site mais acessado no mundo, atrás apenas do Google (ALEXA, 2015). À medida que o Facebook começou a atrair cada vez mais usuários, muitas empresas começaram a se interessar por esta ferramenta como canal de relacionamento com seus clientes, em especial aquelas que prestam serviços exclusivamente pela Internet (Nascimento et al., 2013).

As mídias sociais, assim, constituem-se numa tecnologia caracterizada pela interatividade, personalização de serviços e conteúdos gerados pelos usuários, onde o próprio usuário cria, monta e utiliza-se destes mecanismos conforme o seu interesse, firmando-se como a possível última fronteira da apropriação de tecnologia devido ao seu enorme potencial de transformação da sociedade (ARAÚJO, 2012). Exatamente por essas características peculiares e por esse potencial de transformação citados, o presente estudo vislumbra a apropriação de tecnologia das mídias sociais como um processo de aspectos próprios e que pode, por isso, ser chamado de Apropriação de Mídias Sociais. Tal expressão, até o momento, foi usada por poucos autores e com sentidos diversos, como o de inclusão e participação nas mídias (FLORES, 2013), o de incorporação de uma nova ferramenta (BARRICHELO; WEBER, 2015), ou o da maneira como se usa a tecnologia (ISIKA; MENDOZA; BOSUA, 2015), mas em nenhum dos casos como apropriação de tecnologia de mídias sociais propriamente dita.

Do ponto de vista teórico, um número crescente de estudos tem sido realizado em alguns países sobre a apropriação de tecnologia (ARAÚJO, 2013), com destaque para a Austrália, mas quando considerada justamente a apropriação de tecnologia de mídias sociais constata-se a inexistência de pesquisas, portanto, uma lacuna de conhecimento. É exatamente diante desse contexto e da lacuna de conhecimento ora apresentados que o presente estudo se propõe a apresentar um modelo de análise de apropriação de mídias sociais. 
Este estudo se justifica pelo ineditismo do tema, uma vez que, como já dito, não foram encontrados na literatura trabalhos científicos relacionados à apropriação de tecnologia de mídias sociais. Por outro lado, propor um modelo de análise desse processo de apropriação de tecnologia permite uma melhor visão do comportamento das empresas e dos fatores envolvidos por ocasião do uso de mídias sociais por elas.

\section{Mídias Sociais}

Como é perceptível na literatura, o conceito de mídia social está diretamente atrelado ao de rede social virtual. Para entender o primeiro, portanto, é necessário compreender o segundo. Uma rede social é definida como um conjunto de dois elementos: os atores (pessoas, grupos ou instituições, que são os nós da rede) e suas conexões (interações ou laços sociais). Os atores das redes sociais não são exatamente pessoas, mas sim uma representação delas através de perfis (ou fanpages, quando são empresas) nas redes, expressando elementos de sua personalidade ou individualidade (RECUERO, 2009).

Por outro lado, mídias sociais "podem ser entendidas como a maneira que as empresas classificam as redes sociais, como um canal alternativo de comunicação" (ROCHA et al., 2011, p 2). Para Recuero (2011, p.01), "mídia social é aquela ferramenta de comunicação que permite a emergência das redes sociais". Para que isso ocorra, porém, é necessário que a lógica seguida pela mídia de massa, em que um ator emite para todos, mude e passe a ser utilizada a lógica da participação, em que muitas pessoas emitem e recebem de outras muitas pessoas. Comm $(2009$, p. 02) afirma que é provável que a melhor definição para mídia social seja "o conteúdo que foi criado por seu público". Ou seja, segundo o autor, não há um editor, um redator ou alguém que imponha a informação, podendo qualquer pessoa dividi-la com quem mais tenha interesse. Tais informações e conteúdos, por sua vez, recebem a participação de outras pessoas, como no caso dos blogueiros que postam mensagens e esperam os comentários de seus leitores, criando a expectativa que tais comentários possam agregar novas informações aos publicados por eles, caracterizando o aspecto social desse tipo de mídia (COMM, 2009). Tratase, assim, de uma tecnologia caracterizada pela interatividade, personalização e conteúdos gerados pelos usuários, onde estes criam e utilizam-se desses mecanismos conforme seus interesses (ARAÚJO, 2012).

O crescimento do uso das mídias sociais também ganhou força no meio corporativo, tornando-se uma importante ferramenta de comunicação e marketing para as empresas, permitindo-lhes realizar ações direcionadas de acordo com os perfis de seus usuários e comunidades (SMITH, 2009). Segundo dados do Comitê Gestor da Internet no Brasil (2014, p. 221), referentes ao final do ano de 2013, quatro em cada dez empresas brasileiras estão presentes na Internet por meio de fanpages em mídias sociais e o principal objetivo dessa ação é a busca de maior interatividade com os clientes. Segundo a pesquisa, $74 \%$ dessas empresas utilizam fanpages em mídias sociais para responder a comentários e dúvidas ou para divulgar produtos e serviços.

Mais do que ser um meio de comunicação com o mercado, as redes e as mídias sociais podem conter, muitas vezes, detalhes sobre seus usuários, como hábitos e preferências, locais de trabalho, além de outras características pessoais e demográficas. Tais informações podem se tornar valiosas para uma melhor tomada de decisão em relação a ações para o mercado.

\section{Apropriação de Tecnologia}

Apropriar-se de uma tecnologia é o passo adiante do mero uso desta. Mais do que simplesmente escolher uma ferramenta útil com funcionalidades criadas por seus produtores e fornecedores, trata-se de testar suas possibilidades e modificá-las durante o uso conforme seus desejos e necessidades (CARROLL et al., 2002). As pesquisas sobre a apropriação de tecnologia têm evidenciado a complexidade desse fenômeno, que inclui questões como a da distribuição e redistribuição do controle e do poder de proprietários, fornecedores e usuários sobre as configurações, os usos e os benefícios do artefato ou sistema que sofre apropriação (BAR; PISANI; WEBER, 2007).

Carroll et al. (2001) argumentam que teorias construtivistas sociais sugerem que a tecnologia é formada por uma série de influências, como parte de seu desenvolvimento e, em seguida, é reformulada durante seu uso (BIJKER; LAW, 1992). Além disso, a mesma tecnologia pode ser usada de diferentes maneiras em diferentes contextos, levando a resultados diferentes. Portanto, uma tecnologia não só pode ser adaptada por usuários distintos, mas a mesma tecnologia pode ser interpretada de diversas maneiras, não seguindo um caminho linear ou determinista (CARROLL et al., 2001). Bastos e Brochado (2009) também apontam que a tecnologia, quando fruto de uma apropriação, passa por uma acomodação, uma adaptação, conforme vai sendo absorvida por uma empresa usuária.

Diversos estudos empíricos têm se dedicado à aplicação da apropriação da tecnologia em diferentes áreas do conhecimento, como as pesquisas de Marcolla (2012), na prática pedagógica; Silva (2013), no ensino das 
ciências e da matemática; Maia (2013), em letramentos digitais; Delaney (2010), nas atividades de anestesistas; ou Bastos e Brochado (2009), na indústria da cerâmica. Por outro lado, poucos ainda têm sido os estudos teóricos específicos sobre a apropriação de tecnologia na literatura. Essa lacuna teórica é ocupada basicamente por modelos que se dividem entre as vertentes da apropriação como ressignificação e da apropriação como transformação mediante o uso, modelos estes derivados de teorias que abordam a relação entre o comportamento humano e a tecnologia (ALBERTS, 2013).

No intuito de proporcionar uma visão mais abrangente das teorias de sistemas de informação (SI) que relacionam o comportamento humano e a tecnologia, Alberts (2013) apresenta uma síntese de como essas abordam o uso da tecnologia da informação (Figura 1) e as distingue em três vertentes: estudos de Adoção, a partir da Teoria da Ação Racional (Theory of Reasoned Action); modelos de Apropriação, derivados da Alienação (Alienation), da Teoria da Estruturação (Structuration Theory) e do Construtivismo Social (Social Constructivism); e literatura sociocultural, a partir da Teoria Sociocultural (Sociocultural Theory).

Por serem as que se concentram fortemente sobre o processo de apropriação de uma nova tecnologia, as três teorias dominantes sobre o tema (DELANEY, 2010), a Adaptive Structuring Theory, o Structurational Model of Technology e o Technology Appropriation Model, serão abordadas a seguir.

Figura 1: Visão geral da apropriação na literatura de SI.

Marx

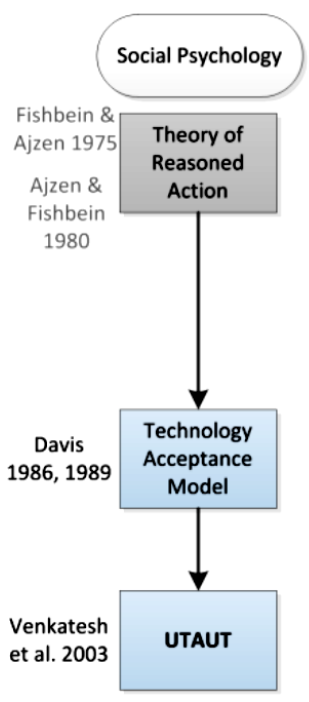

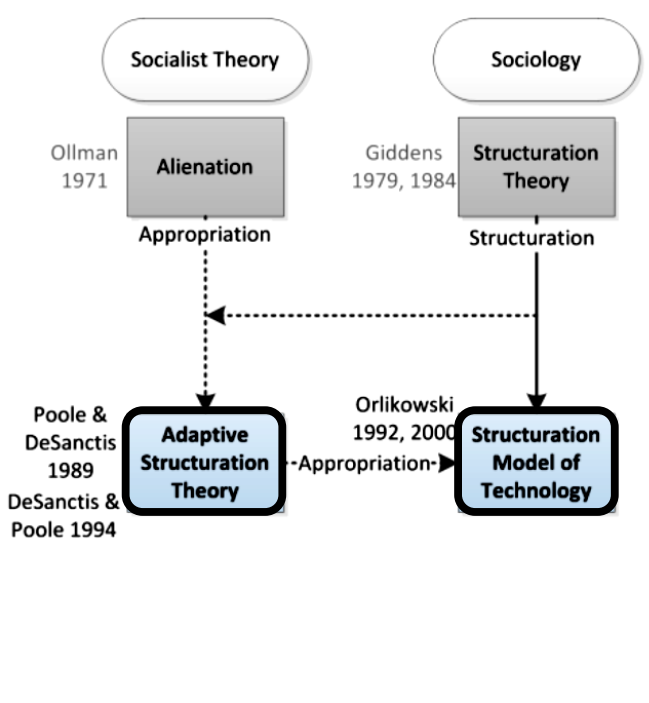

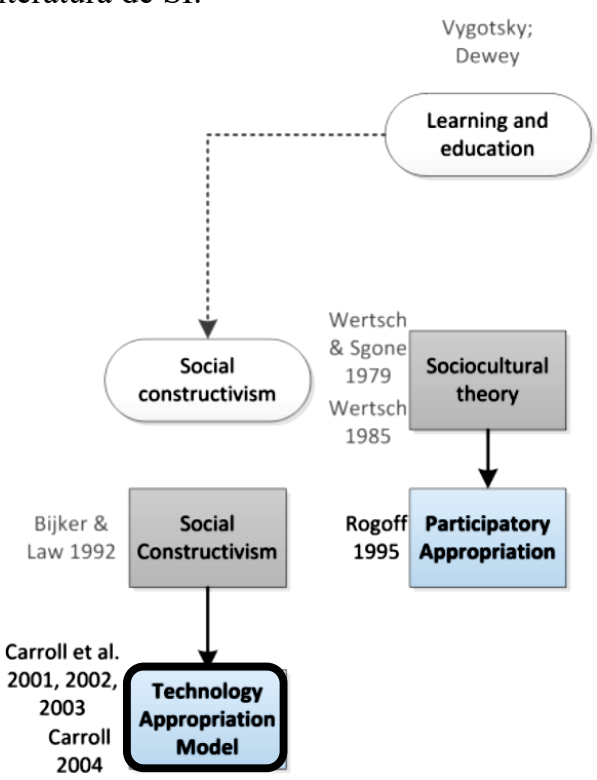

Fonte: Alberts (2013)

\subsection{Teoria da Estruturação Adaptativa}

Primeiramente, a Teoria da Estruturação Adaptativa (Adaptive Structuring Theory - AST), de Poole e DeSanctis (1989), foi o primeiro estudo sobre apropriação de tecnologia e suas aplicações na área de sistemas de informação. A AST se constitui numa teoria do uso da tecnologia desenvolvida a partir de dois conceitos importantes, a Estruturação, de Giddens (1979), que se constitui em colocar uma característica estrutural em ação, e ao fazê-lo produzir e reproduzir estruturas sociais; e a Apropriação, de Ollman (1971), que são aquelas ações que apontam para processos de estruturação (ALBERTS, 2013). Inicialmente, para Poole e DeSanctis, apropriação tratava-se do processo de alteração, por parte dos usuários, de um sistema por eles utilizado. Posteriormente, os autores mudaram o conceito para "as ações visíveis imediatas que evidenciam processos de estruturação mais profundos” (DESANCTIS; POOLE, 1994, p. 128).

Assim, a tecnologia fornece estruturas sociais que podem ser descritas em suas características estruturais e no espírito da tecnologia (DESANCTIS; POOLE, 1994). Entendem-se por características estruturais as capacidades oferecidas por uma tecnologia, enquanto espírito da tecnologia se trata da intenção geral, da promoção de determinados valores subjacentes a um conjunto de funcionalidades.

A AST, portanto, apresenta quatro aspectos para o processo de apropriação: os movimentos de apropriação, a fidelidade da apropriação, os usos instrumentais e as atitudes. Os movimentos de apropriação são as ações dos usuários no sentido de usar diretamente o sistema, relacioná-lo com outras estruturas, restringir o seu uso ou fazer algum julgamento sobre o mesmo, seja ele positivo ou negativo. Já a fidelidade da apropriação está 
relacionada à consonância entre a utilização e o espírito da tecnologia, podendo ser considerada fiel ou infiel, mas destacando que tal fidelidade em nada se refere à qualidade da tecnologia. Os usos instrumentais, por sua vez, dizem respeito à finalidade da tecnologia, sejam elas atividades, processos de gerenciamento de grupo ou outras influências. As atitudes, por fim, apontam para as experiências dos usuários no uso da tecnologia, sejam elas de comodidade ou de desafio (DESANCTIS; POOLE, 1994).

Ao descrever o uso da tecnologia, Poole e DeSanctis (1989) utilizam a apropriação no intuito de explicar que o significado da tecnologia é dinâmico. Os usuários muitas vezes alteram o sistema durante o uso, apropriando-se da tecnologia, e não a usando apenas de modo pré-definido. Mais do que isso, a própria tecnologia é passível de mudanças à medida que as pessoas modificam sua maneira de usá-la, podendo ser usada de formas distintas por diferentes usuários (POOLE; DESANCTIS, 1989). Pode-se dizer, então, que o ponto principal desta teoria é a ideia de que a tecnologia não é estática, mas, sim, dinâmica à medida que os usuários atribuem significado a ela no processo de apropriação, ideia esta que acabou por viabilizar um grande avanço à literatura da área de Sistemas de Informação (ALBERTS, 2013).

\subsection{Modelo Estruturacional de Tecnologia}

O segundo modelo, de Orlikowski (1992), é o Modelo Estruturacional de Tecnologia (Structurational Model of Technology - SMT), que fornece uma interpretação da tecnologia como um tipo de estruturas, o que aumenta a noção de que ela intermedia a percepção e as ações do usuário. Mais próximo da Teoria da Estruturação, de Giddens (1979), o modelo considera que o usuário atribui significado à tecnologia ao apropriar-se dela, conferindo-lhe a condição de co-constituído pela tecnologia. Essa abordagem deriva do conceito de estruturação que considera que as regras e recursos produzidos e reproduzidos pelas pessoas em suas relações sociais tornamse padronizadas e institucionalizadas com o tempo, formando propriedades estruturais (de uma organização). Ou seja, as mesmas regras e os mesmos recursos que mediam as ações sociais são, ao mesmo tempo, reafirmados por essas mesmas ações, a chamada dualidade da estrutura (ALBERTS, 2013). Orlikowski (1992), então, sugere que a tecnologia seja entendida como um tipo de propriedade estrutural, relacionada aos agentes humanos, tornando-se uma espécie de instanciação de algumas das regras e recursos que constituem a estrutura organizacional.

O SMT se consiste em três componentes que partilham quatro relações principais, conforme Figura 2. Os três componentes são: os agentes humanos (humanagents), a tecnologia (technology) e as propriedades institucionais ou estruturas (institucional properties).

Quanto às relações, a primeira, entre agentes humanos e tecnologia, (a) é chamada de "tecnologia como um produto da ação humana", que considera que os indivíduos atribuem significado compartilhado com a tecnologia por ocasião da apropriação de uma tecnologia, noção esta semelhante à de Poole e DeSanctis (1989). A segunda relação, entre a tecnologia e os agentes humanos, (b) é chamada de "tecnologia como um meio da ação humana", levando-se em conta que a tecnologia medeia atividades, facilitando ou restringindo simultaneamente o desempenho de certos tipos de trabalho.

A terceira relação, por sua vez, (c) é chamada de "condições institucionais de interação com a tecnologia", ligando a estrutura ao agente humano, e considera que o uso da tecnologia é mediado pelas regras e recursos da estrutura social, sofrendo, assim, as influências das estruturas sociais e permitindo que uma mesma tecnologia possa ser apropriada de maneiras distintas por indivíduos diferentes. A quarta e última relação, por fim, entre a tecnologia e as estruturas, (d) é chamada de "consequências institucionais de interação com a tecnologia", remetendo à ideia original de estruturas e lembrando que, em uso e apropriação da tecnologia, há um feedback para as regras e os recursos extraídos, podendo estes serem reafirmados ou modificados.

Figura 2: Modelo Estruturacional de Tecnologia.

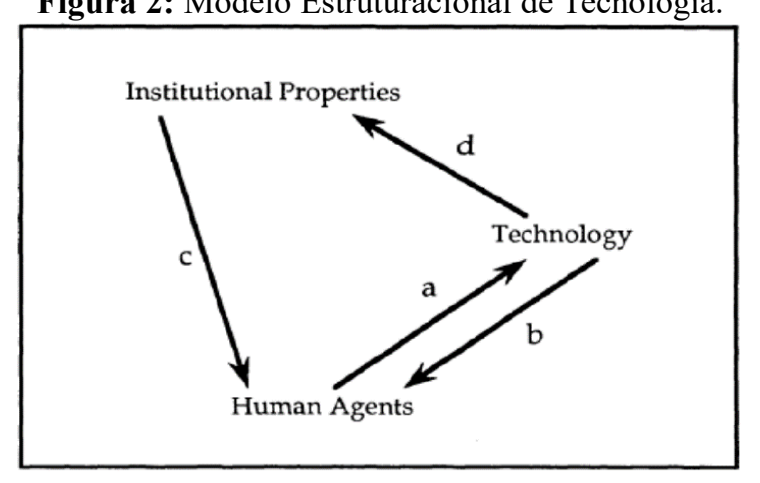


Fonte: Orlikowski (1992).

Pode-se notar aqui que o SMT, de Orlikowski, se assemelha à AST, de Poole e DeSanctis, quanto ao aspecto dinâmico da tecnologia no processo de apropriação, mas o modelo de Orlikowski (1992) vai ainda além, aproximando-se mais da Teoria da Estruturação.

\subsection{Modelo de Apropriação de Tecnologia (MTA) - 2002}

O terceiro, por fim, é o Modelo da Apropriação de Tecnologia (Modelof Technology Appropriation - MTA e anteriormente chamado de Technology Appropriation Model), de Carroll et al. (2001 e 2002), que foi desenvolvido na primeira década dos anos 2000 como resultado de um estudo exploratório dos usos cotidianos de tecnologias móveis (basicamente telefones celulares e SMS) por jovens australianos na faixa etária de 16 a 22 anos em contextos de estudo, lazer, trabalho e socialização. O resultado da pesquisa, que tinha por objetivo compreender os motivos que justificavam a enorme popularidade dessas tecnologias, levou os autores a elaborarem um modelo conceitual de um processo percebido de apropriação. Araújo (2013) lembra que o estudo foi pioneiro porque, até então, apenas eram investigados os usos de sistemas tecnológicos corporativos em contextos de trabalho.

Carroll et al. registraram de forma abrangente os usos cotidianos das tecnologias móveis pelos jovens, bem como suas percepções e atitudes em relação a elas. Dessa forma, os autores conseguiram descrever fatores que tornam as tecnologias móveis atraentes para os jovens e assim construir uma teoria do processo por meio do qual esses usuários adotam e adaptam essas tecnologias segundo suas necessidades (CARROLL et al., 2002, p. 1777).

O Modelo de Apropriação de Tecnologia, de Carroll et al. (2002), portanto, como exposto na Figura 3, considera a transformação da tecnologia no processo de apropriação, distinguindo a tecnologia como projetada e a tecnologia em uso, abordando o processo de transformações pelo qual, a partir de um conjunto de condições iniciais (a tecnologia como projetada), chega-se a um estado final (a tecnologia em uso). A tecnologia como projetada se apresenta como um componente que contém um modelo implícito do usuário pretendido, incluindo certas regras a respeito das atividades a serem executadas. Tais regras envolvem recursos necessários à realização dessas atividades, suposições sobre as características do usuário e conhecimentos e normas que refletem os processos pelos quais as atividades são executadas. Por essas razões, segundo os autores, a tecnologia como projetada oferece funções que propiciam ou restringem as ações dos usuários.

Figura 3: Modelo Apropriação de Tecnologia

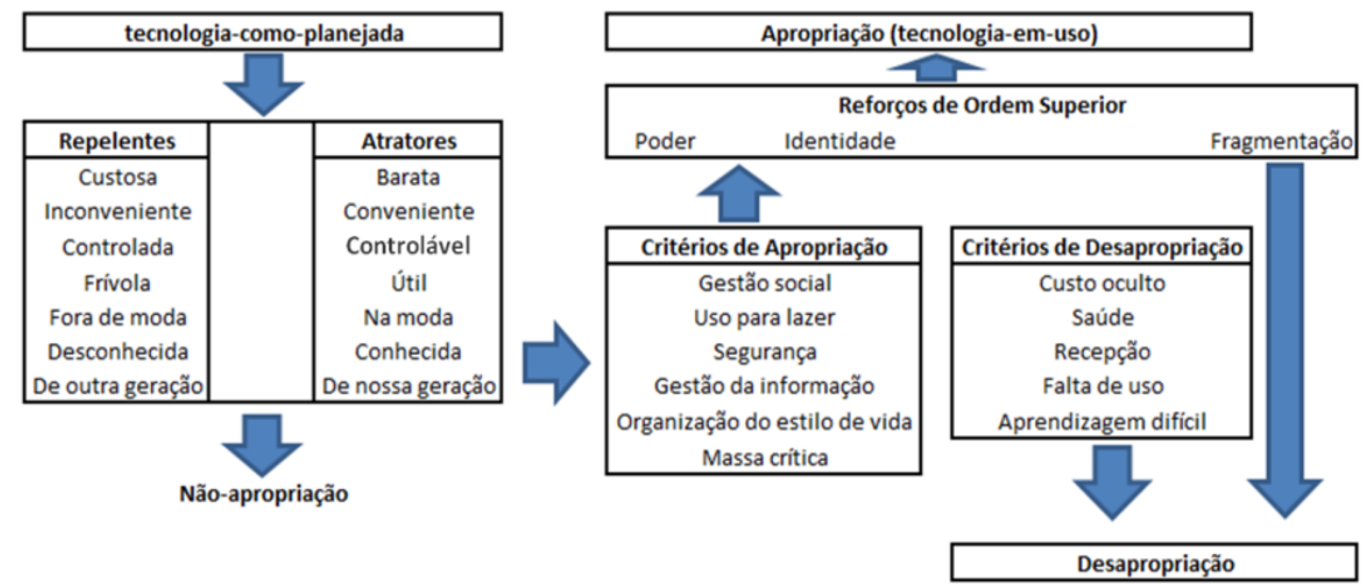

Fonte: Carroll et al. (2002)

Esses usuários, por sua vez, são atraídos ao uso, à experimentação e à avaliação de tecnologias que, por exemplo, se revelam acessíveis, convenientes e controláveis, e que apoiam suas atividades sociais. A decisão dos usuários de explorar uma tecnologia é resultante principalmente da presença do que Carroll et al. (2002) chamaram de "atratores", dando início ao processo de apropriação, que pode resultar na integração dessa tecnologia à vida cotidiana, passando a constituir a tecnologia em uso.

Os atratores funcionam como um filtro inicial por meio do qual os usuários decidem se uma tecnologia satisfaz seus requisitos gerais para se tornar um instrumento de uso em seu cotidiano. Caso ela não os atenda, não será considerada para adoção, também não sofrendo, portanto, a apropriação. Por outro lado, uma tecnologia que não satisfaz as necessidades dos usuários ou apresenta aspectos indesejados, os fatores "repelentes", é candidata à simples não-apropriação. 
Os critérios de apropriação, por sua vez, atuam dentro do processo após a análise inicial. Segundo o modelo, por meio deles é feita outra análise, desta vez sob o foco das contribuições da tecnologia para diversos aspectos da vida social ou do estilo de vida de seus usuários. Uma vez que a tecnologia tenha sido apropriada, fatores de reforço de ordem superior passam a atuar como forças importantes para reforçar seu uso e promover sua estabilização (CARROLL et al., 2001). Em consequência, essa tecnologia passará a "moldar as necessidades e as vidas dos usuários, oferecendo novas formas de viver e de interagir como mundo" (CARROLL et al., 2002, p. 1783). Uma tecnologia que tenha sido apropriada e estabilizada, porém, poderá eventualmente sofrer "desapropriação" e rejeição mediante sua reavaliação, por exemplo, como resposta a mudanças em fatores contextuais que a tornem pouco atraente para seus usuários.

Diversos estudos utilizaram este modelo de Carroll et al. (2002), como os de Araújo (2013), Isika, Mendoza e Bosua (2015), Rahim e Alias (2006) e Ylipulli et al. (2014).

\subsection{Modelo de Apropriação de Tecnologia (MTA) - 2004}

Com o avanço das pesquisas de Carroll sobre apropriação de tecnologia, a autora apresentou um novo modelo com alterações que permitiram uma visão mais ampla do processo não apenas envolvendo aspectos de pessoas físicas, característicos do modelo anterior (CARROLL, 2004). A autora retoma a discussão sobre a avaliação inicial da tecnologia por parte do usuário individual (tecnologia como projetada / technology as designed) como parte do processo de adoção, levando-o a aceitar ou não (não adoção / non adoption) a nova tecnologia (Nível 1 na Figura 4). Uma vez adotada, o compromisso com a tecnologia é evidente quando o usuário passa a usá-la e investe tempo e esforço para explorá-la, examinando o que ela oferece e aplicando-a na prática (exploration \& adaptation) (Nível 2 na Figura 4). A tecnologia como projetada, então, sempre será, em certo sentido, pouco familiar para os usuários e aberta à interpretação destes para "desempacotá-la" a fim de compreender a melhor maneira de como ela funciona, independentemente do tempo necessário para tal (CARROLL; FIDOCK, 2011). Nesse processo normalmente ocorre um desvio das expectativas iniciais para a percepção da tecnologia como um resultado da exploração ou do uso na prática, onde as ações dos usuários são influenciadas pelo contexto do uso e pelas contingências particulares enfrentadas.

Figura 4: Modelo de Apropriação de Tecnologia

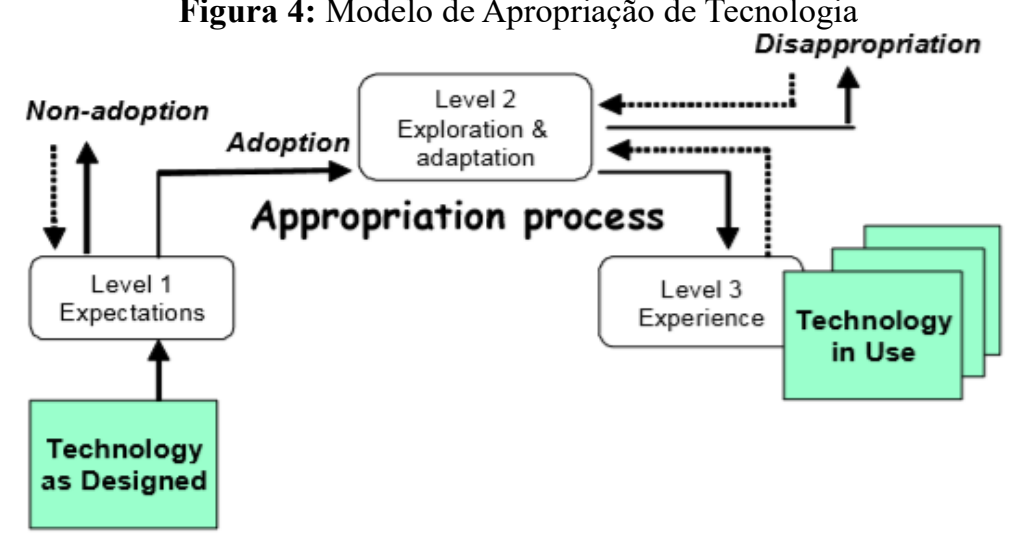

Fonte: Carroll e Fidock (2011) adaptado de Carroll (2004).

Durante a etapa de exploração da tecnologia (Nível 2 na Figura 4), os usuários podem nela realizar adaptações de aparência ou interface, testar diferentes aplicações isoladas ou combinadas com outras tecnologias etc. Nem todas as tecnologias, porém, são igualmente adaptáveis, podendo algumas serem mais maleáveis ou capazes de serem moldadas em diferentes situações, enquanto outras permitem menos adaptação de suas qualidades materiais. Além disso, uma tecnologia pode ser aplicada pelo usuário para um propósito novo e inesperado, dependendo mais da imaginação do usuário do que da qualidade material da tecnologia. Destaque-se, porém, que adaptar a tecnologia é apenas uma parte do processo de apropriação, uma vez que, simultaneamente, os usuários adéquam suas próprias práticas em decorrência do uso da tecnologia, seja em consonância com o evidente objetivo de implementação de novas tecnologias (para alterar processos ou práticas), seja por formas inesperadas (CARROLL; FIDOCK, 2011).

Um possível resultado desse processo de exploração é a desapropriação, onde são rejeitadas algumas características ou funcionalidades tecnológicas ou mesmo a tecnologia como um todo. Ao longo do tempo, a consciente avaliação, exploração e adaptação por parte do usuário tende a diminuir (Nível 3 na Figura 4), podendo a tecnologia tornar-se parte integrante das práticas do usuário (tecnologia em uso). No entanto, tal estabilização está condicionada a possíveis reavaliações (linha pontilhada do Nível 3 para o Nível 2 na Figura 4), 
com as consequentes confirmações de apropriação, apropriação parcial ou interrupção (desapropriação) da respectiva tecnologia (CARROLL; FIDOCK, 2011).

As várias instâncias de tecnologia em uso, constantes no final da Figura 4, sinalizam que diferentes usuários podem apropriar-se de uma tecnologia de maneiras diferentes, coincidindo com a experiência dos usuários (Nível 3), uma vez que ambos estão fortemente entrelaçados na prática. A tecnologia, portanto, como também sinalizado por Orlikowski (1992), acaba por ser co-projetada pelos usuários de acordo com suas necessidades, contextos de uso e práticas.

Para Carroll (2004), este não é um padrão pré-determinado: os usuários percebem uma tecnologia de maneiras diferentes, seja como uma oportunidade ou solução, seja como um problema; algumas delas serão imediatamente acessíveis para novos usuários, enquanto outras são mais complexas. Provavelmente o tempo e o padrão de adaptação variem em diferentes situações, influenciados pelos custos de se adaptar ou não à tecnologia, pela flexibilidade dos processos organizacionais, ou pela capacidade pessoal de inovação e de adaptação dos usuários. Estes, portanto, podem adotar e usar algumas funções de uma tecnologia e não outras, podem personalizar ou reconfigurar características da tecnologia, podem usá-la de maneiras inesperadas e podem mudar suas atividades para acomodá-la (CARROLL; FIDOCK, 2011).

\section{Modelo Proposto de Apropriação de Mídias Sociais - MTA Adaptado}

Diante dos modelos apresentados, o presente estudo optou por tomar como base o MTA, de Carroll, por ser o que melhor caracteriza o processo da apropriação e suas etapas. A escolha do MTA, porém, precisa levar em consideração alguns aspectos. Primeiramente, o MTA sugerido em 2002 (CARROLL et al., 2002) mostra-se bem detalhado em suas dimensões, mas é resultante de comportamentos de pessoas físicas. Por outro lado, o MTA proposto em 2004 (CARROLL, 2004) apresenta um aspecto mais generalista, mas sem dimensões de análise específicas. Outro aspecto, ainda, é que o foco deste estudo é a apropriação de mídias sociais especificamente por parte de empresas, ou seja, nem voltado para pessoas físicas como o primeiro modelo, nem tão generalista como o segundo.

Este artigo, portanto, vem propor um modelo de análise adaptado dos MTAs de Carroll et al. (2002) e Carroll (2004) (Figura 5), apresentando a mesma estrutura do MTA de 2004, mas lançando mão dos fatores sugeridos no MTA de 2002. No caso específico destes fatores, foram propostas algumas adaptações nos termos originais utilizados pelos autores, visando palavras mais específicas que possam contribuir com a análise. No Nível 1, por exemplo, foi introduzida a expressão Fatores de Adoção visando reunir os originais Fatores Atratores e Fatores Repelentes do MTA de 2002. No Nível 2, inserida a expressão Fatores Intermediários, relacionados aos Critérios de Apropriação e Desapropriação do mesmo modelo, e finalmente a inserção do termo Fatores Reforçadores no Nível 3 que se relacionam aos Reforços de Ordem Superior do modelo original.

Figura 5: Modelo de Apropriação de Mídias Sociais 


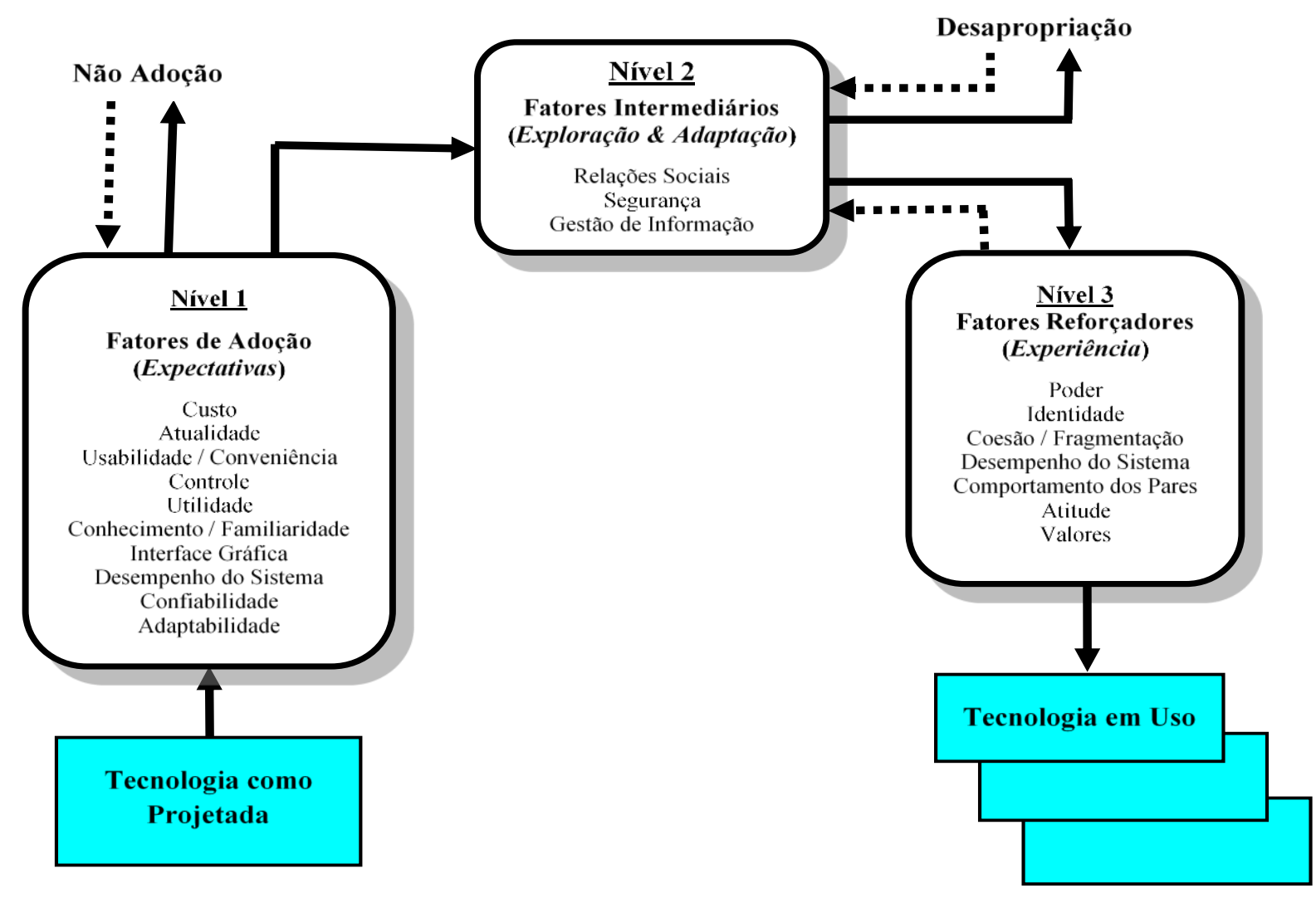

Fonte: adaptado de Carroll et al. (2002) e Carroll (2004)

Considerando, desse modo, que o modelo ora proposto se refere à apropriação de mídias sociais, os fatores nele incluídos são formados por dimensões direcionadas a esta tecnologia, sejam baseadas naquelas apresentadas por Carroll et al. (2002), sejam as sugeridas na literatura por Davis (1989); Fidock e Carroll (2006); Mendoza, Carroll e Stern (2005); ou Ylipulli et al. (2014), porém, com algumas mudanças sugeridas de nomenclatura para melhor visualização.

O modelo proposto, então, considera que as mídias sociais são projetadas por seus desenvolvedores dentro de perspectivas e critérios por eles definidos, mas não necessariamente de acordo com as expectativas dos usuários, até por essas serem bastante variadas e diversas. Levando-se em consideração tratar-se de empresas como possíveis usuárias dessas mídias, os Fatores de Adoção (Nível 1) se referem às expectativas que as mesmas têm em relação ao uso das mídias e aos possíveis resultados obtidos com este uso. Esses Fatores de Adoção, segundo o modelo proposto, envolvem as seguintes dimensões: Custo (CARROLL et al., 2002), considerando custos de manutenção da fanpage, de serviços específicos oferecidos pelo mídia social e com profissional qualificado para operação; Atualidade (CARROLL et al., 2002), abordando aspectos novos da tecnologia e o fato de tanto empresas como pessoas usarem a mídia social na ; Controle (CARROLL et al., 2002) considerando a necessidade de profissional qualificado e necessidade de serviço terceirizado; Conveniência e Usabilidade (Carroll et al., 2002; Davis, 1989), englobando facilidade de aprendizado, facilidade de uso, necessidade de conhecimento prévio da tecnologia e funções e comandos fáceis e acessíveis; Utilidade e Recursos (CARROLL et al., 2002; Davis, 1989), que envolvem a variedade, a disponibilidade e a abrangência dos recursos da tecnologia; Conhecimento e Familiaridade (CARROLL et al., 2002, ALBUQUERQUE, 2009), considerando o envolvendo domínio da linguagem, as informação sobre recursos e sobre possibilidades de aplicações; Interface Gráfica (FIDOCK; CARROLL, 2006), envolvendo ambiente virtual amigável e aparência visual agradável; Desempenho do Sistema (FIDOCK; CARROLL, 2006), avaliando a rapidez de processamento; Confiabilidade do Sistema (FIDOCK; CARROLL, 2006), observando a sensação de segurança ao se usar o sistema; e a Adaptabilidade (MENDOZA; CARROLL; STERN, 2005), envolvendo a possibilidade de adequações e ajustes e a possibilidade de adaptação tipo "do it yourself". A presença e a intensidade desses Fatores de Adoção responderão pela adoção ou não das mídias sociais. Ressalte-se que, como visto na Figura 5, a não adoção da mídia social não é necessariamente definitiva. A presença desses Fatores pode influenciar uma possível adoção da tecnologia em outro momento. 
Uma vez adotada a mídia social, ocorrerá a etapa de experimentação e possível adaptação dessa tecnologia - o Nível 2 do modelo. Os fatores que incidem nesta fase do processo são os Intermediários que englobam as seguintes dimensões: Relações Sociais (CARROLL et al., 2002), envolvendo linguagem acessível e a possibilidade de funcionários diversos utilizarem a tecnologia; Segurança (CARROLL et al., 2002), englobando segurança contra invasões do sistema (hackers), confiabilidade nas informações recebidas e constância do sistema; e Gestão de Informação (CARROLL et al., 2002), considerando a possibilidade de tabular e analisar dados gerados no sistema, a disponibilidade de dados secundários fornecidos pelo sistema $\mathrm{e} o$ fornecimento de informações, pelo sistema, que permitam a melhoria da tomada de decisão. Assim como ocorre no Nível 1, é a presença e a intensidade desses fatores que podem levar a empresa a usar efetivamente a mídia social adotada ou descartá-la, já como uma desapropriação. Também como ocorre no Nível 1, a desapropriação da mídia social não é necessariamente definitiva, podendo esta voltar a ser usada pela empresa em outro momento conforme a presença dos fatores envolvidos.

As mídias sociais adotadas, usadas e não descartadas pela empresa, então, tendem a se tornar parte de sua rotina. É nessa etapa, a da experiência, Nível 3, que as tecnologias são ajustadas e definitivamente incorporadas às atividades da organização. Aqui incidem os Fatores Reforçadores, que apresentam as seguintes dimensões: Poder (CARROLL et al., 2002), envolvendo a amplitude da audiência e o destaque em relação à concorrência; Identidade (CARROLL et al., 2002), considerando a imagem da empresa atrelada à mídia e ser essa mídia social a principal localização da empresa na internet; Fragmentação (CARROLL et al., 2002), com a possibilidade de reunião de vários recursos num mesmo sistema e a possibilidade de comunicação direta com outros sistemas; Desempenho do Sistema (FIDOCK; CARROLL, 2006), englobando o atendimento das expectativas da empresa e a geração de bons resultados; Comportamento dos Pares (FIDOCK; CARROLL, 2006), considerando o uso da mesma tecnologia pelos pares e o investimento dos pares no sistema; Atitude (YLIPULLI et al., 2014), avaliando o incentivo à pró-atividade e o estímulo à criatividade; e por fim Valores (YLIPULLI et al., 2014), envolvendo o reforço dos valores da empresa e relação com os valores da mídia adotada. É a presença e a intensidade desses Fatores Reforçadores que podem confirmar a apropriação da mídia social pela empresa que a adotou e a levará ao estágio final do processo, de Tecnologia em Uso. Ressalte-se que no modelo proposto, assim como no modelo de Carroll (2004), as Tecnologias em Uso podem ser diversas, variando de acordo com a empresa, com as adaptações e os ajustes feitos e com os diversos possíveis usos dados a tecnologia.

A sequência apresentada, portanto, compõe o processo proposto de apropriação das mídias sociais, desde a etapa da Tecnologia como Projetada até Tecnologia em Uso, passando pelos três níveis aqui apresentados.

\section{Considerações Finais}

A projeção e proliferação das mídias sociais nos últimos anos proporcionaram uma maior interação entre usuários e empresas devido à sua flexibilidade, rapidez e alcance, permitindo uma comunicação mais direta, ágil, interativa e precisa. Por outro lado, nem todos utilizam as mídias sociais, assim como as demais tecnologias, em conformidade com o uso originalmente concebido pelo desenvolvedor. Esse processo de ajuste e adaptação das tecnologias de acordo com os interesses e conveniências de quem as utiliza recebe o nome de apropriação.

O presente artigo visa propor um modelo de apropriação de mídias sociais baseado nos Modelos de Apropriação de Tecnologia (MTA) de Carroll et al. (2002) e Carroll (2004). Tal modelo se propõe a identificar características peculiares no processo de apropriação de mídias sociais por empresas, englobando tanto os Fatores de Adoção, no primeiro estágio do processo, quanto os Fatores Intermediários, que envolvem a exploração e a adaptação da tecnologia, até os Fatores Reforçadores, fundamentais para a consolidação da apropriação ou não.

Esse modelo é útil por proporcionar de modo simples uma visão do processo de apropriação de mídias sociais por parte de empresas e dos fatores que o constituem. Tal visão pode permitir uma compreensão mais apurada do funcionamento dessas tecnologias em diferentes realidades empresariais e em diversos usos, diferentemente da função para a qual foram projetadas.

A importância do modelo proposto também pode ser notada na identificação de dimensões e características próprias de mídias sociais que permitam observar de modo mais detalhado o processo de apropriação desta tecnologia, assim como seu mapeamento. Ou seja, conhecer e compreender esse processo de apropriação de mídias sociais pode viabilizar um melhor entendimento de como empresas adotam e usam essas mídias, e quais fatores são importantes nesse processo. O modelo, assim, pode ser usado por pesquisadores e profissionais que tenham por objetivo aprimorar-se tanto na pesquisa de apropriação de tecnologia, quanto no campo das mídias sociais.

Sua aplicação pode se dar por meio de investigação direta nas organizações. Tal investigação pode ocorrer sob o 
formato de entrevista estruturada com seus gestores e profissionais que atuam diretamente com suas mídias sociais, quando será possível identificar as razões da adoção ou não das respectivas mídias, contemplando, assim, os aspectos abordados no Nível 1 do modelo. A mesma técnica também permite identificar os aspectos abordados no Nível 2 e no Nível 3 do modelo, as formas de uso e de apropriação propriamente dita, respectivamente. Tal investigação, ressalte-se, não dispensa a utilização da observação de site (web analisys) para a devida verificação das informações levantadas por meio das entrevistas.

Se, por um lado, as dimensões abordadas no modelo podem ser utilizadas para todas as mídias sociais, por outro, tal abrangência das dimensões não chega a propiciar análises mais apuradas de cada mídia em particular com suas peculiaridades, constituindo-se, assim, uma limitação do presente estudo. De outro modo, a busca de dimensões e indicadores referentes à adoção e à apropriação de tecnologia de cada mídia social pode ser uma sugestão para trabalhos futuros, assim como a criação de modelos específicos para diferentes mídias, especialmente o Facebook, ou o comparativo entre diferentes modelos de apropriação de mídias sociais.

\section{Referências}

ALBERTS, B. Technology appropriation revisited - mediation theory as a new philosophy of technology for information systems research. Master thesis, Business Information Technology, School of Management and Governance, University of Twente, Enschede, Netherland, 2013.

ALEXA. How popular is Facebook.com? 2015. Disponível em <http://www.alexa.com/siteinfo/facebook.com>. Acesso em 15 Fev. 2016.

ARAÚJO, J. P. Apropriação, participação e aprendizagem no YouTube. Linguagens e Diálogos, v. 3, n. 1, p. 128, 2012.

ARAÚJO, J. P. O Robô Ed é Meu Amigo - apropriação de tecnologia à luz da Teoria da Atividade. Tese de Doutorado, Programa Interdisciplinar de Pós-Graduação em Linguística Aplicada, Faculdade de Letras, Universidade Federal do Rio de Janeiro, Rio de Janeiro, 2013.

BAR, F.; PISANI, F.; WEBER, M. Mobile technology appropriation in a distant mirror: baroque infiltration, creolization and cannibalism. SEMINARIO SOBRE DESARROLLO ECONÓMICO, DESARROLLO SOCIAL Y COMUNICACIONES MÓVILESEN AMÉRICA LATINA, 2007, Buenos Aires, Argentina.

BARICHELLO, E. M. M. R.; WEBER, C. T. Apontamentos sobre visibilidade institucional: estratégias de apropriação de mídias sociais digitais em produtos hipermidiáticos jornalísticos. Culturas Midiáticas, v. 8, n. 2, 2015.

BASTOS, S. S.; Brochado, M R. Modelo de apropriação de tecnologia: caso da indústria de cerâmica vermelha. Gestão \& Produção, v. 16, n. 4, p. 544-555, São Carlos, SP, 2009.

BIJKER, W. E.; LAW, J. Shaping technology/building society: Studies in sociotechnical change. MIT press, 1992.

CARROLL, J. Completing design in use: closing the appropriation cycle. In: EUROPEAN CONFERENCE ON INFORMATION SYSTEMS, 2004, Turku, Finland. Anais...

CARROLL, J. et al. Identity, power and fragmentation in cyberspace: technology appropriation by young people. ACIS - AUSTRALIAN CONFERENCE ON INFORMATION SYSTEMS, 2001, Anais...

CARROLL, J. et al. Just what do the youth of today want? Technology appropriation by young people. In System Sciences, 2002. HICSS. PROCEEDINGS OF THE 35TH ANNUAL HAWAII INTERNATIONAL CONFERENCE ONSYSTEM SCIENCES (pp. 1777-1785). IEEE.

CARROLL, J.; FIDOCK, J. Beyond resistance to technology appropriation. In: HAWAII INTERNATIONAL CONFERENCE ON SYSTEM SCIENCES, 44, 2011. Koloa, Hawaii, USA. Anais..., IEEE.

COMITÊ GESTOR DA INTERNET NO BRASIL. Pesquisa sobre o uso das tecnologias da informação e da comunicação no setor público brasileiro: TIC governo eletrônico. São Paulo: Comitê Gestor da Internet no Brasil, 2014.

COMM, J. O poder do Twitter: estratégias para dominar seu mercado e atingir seus objetivos com um tweet por vez. São Paulo, Gente, 2009.

DAVIS, F. D. Perceived usefulness, perceived ease of use, and user acceptance of information technology. MIS Quarterly, v. 13, n. 3, p. 319-340, 1989. 
DELANEY, P. J. A Grounded Theory Study of Technology Appropriation in Anesthesia. Doctoral Thesis, Faculty of Science And Technology, Queensland University of Technology, Brisbane, QLD, Australia, 2010.

DESANCTIS, G.; POOLE, M. Capturing the complexity in advanced technology use: Adaptive Structuration Theory. Organization Science, v. 5, n. 2, p. 121-147, 1994.

FIDOCK, J.; CARROLL, J. The model of technology appropriation: a lens for understanding systems integration in a defence context. In: AUSTRALASIAN CONFERENCE ON INFORMATION SYSTEMS, 17, 2006. Adelaide, Australia. Anais...

FLORES, N. Blogs de ciência: práticas de cuidado de si do cientista contemporâneo. Animus. Revista Interamericana de Comunicação Midiática, v. 12, n. 23, 2013.

GIDDENS, A. Central Problems in Social Theory. University of California Press, Berkeley, CA, 1979.

ISIKA, N. U.; MENDOZA, A.; BOSUA, R. Appropriation of social media by patients with chronic illness to share knowledge. In: AUSTRALASIAN CONFERENCE ON INFORMATION SYSTEMS, 26, 2015. Adelaide, Australia. Anais...

MAIA, J. O. Apropriação dos letramentos digitais para participação social mais ampla: um estudo de caso. Dissertação de Mestrado, Instituto de Estudos da Linguagem da Universidade Estadual de Campinas, Campinas, SP, 2013.

MARCOLLA, V. Apropriação das tecnologias de informação e comunicação por professores nas práticas pedagógicas. In: SEMINÁRIO DE PESQUISA EM EDUCAÇÃO DA REGIÃO SUL, 9. 2012. Caxias do Sul, RS. Anais... UCS.

MENDOZA, A.; CARROLL, J.; STERN, L. Adoption, adaption, stabilization and stagnation: software appropriation over time. In AUSTRALASIAN CONFERENCE ON INFORMATION SYSTEMS, 2005 (pp. 111). University of Technology, Sydney.

NASCIMENTO et al. O uso do Facebook no Relacionamento com o Cliente: um estudo comparativo entre Pequenas Empresas Físicas e Virtuais. In: ENCONTRO DE ADMINISTRAÇÃO DA INFORMAÇÃO, 2013. Anais...

OLLMAN, B. Alienation: Marx' conception of man in capitalist society. Cambridge University Press, 1971.

ORLIKOWSKI, W. J. The duality of technology: rethinking the concept of technology in organizations. Organization Science, v. 3, n. 3, p.398-427, 1992.

POOLE, M. S.; DESANCTIS, G. Use of group decision support systems as an appropriation process. In: System Sciences, 1989. Vol. IV: Emerging Technologies and Applications Track, Proceedings of the Twenty-Second Annual Hawaii International Conference on. IEEE. p. 149-157.

QUALMAN, E. Socialnomics: como as mídias sociais estão transformando a forma como vivemos e fazemos negócios. São Paulo, Saraiva, 2011.

RAHIM, N. Z. A.; ALIAS, R. A.. Open Source Software Appropriation in Malaysian Public Sector. In: PROCEEDINGS OF THE POSTGRADUATE ANNUAL RESEARCH SEMINAR. 2006.

RECUERO, R. Redes sociais na internet. Porto Alegre, Sulina, 2009.

RECUERO, R. O que é mídia social?, 2011. Disponível em $<$ http://www.pontomidia.com.br/raquel/arquivos/o_que_e_midia_social.html $>$. Acesso em 12 Set. 2014.

ROCHA et al. O uso das redes sociais na construção do relacionamento com clientes: um estudo de caso múltiplo no Brasil. XXXV ENCONTRO DA ANPAD, 35, 1679-1827. 2011. Anais...

RODRIGUEZ, C. L. O movimento de apropriação das tecnologias da informação e comunicação (TIC) por adultos escolarizados em exercício de sua profissão: um estudo com agentes comunitários de saúde. Dissertação de Mestrado, Universidade Estadual de Campinas, Campinas, SP, 2006.

SAAD CORRÊA, E. N. Comunicação digital e novas mídias institucionais. In: KUNSCH, M. M. K. (Org.). Comunicação organizacional, São Paulo, Saraiva, p. 317-335, 2009.

SILVA, A. M. T. B. O processo de apropriação das tecnologias na prática profissional dos docentes da área do ensino das ciências e matemática: um estudo preliminar a partir da teoria das representações sociais. Alexandria Revista de Educação em Ciência e Tecnologia, v. 6, n. 2, p. 33-52, 2013.

SMITH, T. The social media revolution. International Journal of Market Research, v. 51, n. 4, 2009. 
Silva, A. S. R.; Santos, E. M.

Revista Gestão.Org, v. 15, Edição Especial, 2017. p. 171-183

ISSN 1679-1827

http://www.revista.ufpe.br/gestaoorg

YLIPULLI, J. et al. Municipal WiFi and interactive displays: appropriation of new technologies in public urban spaces. Technological Forecasting and Social Change, 89, p. 145-160, 2014. 